\title{
Entre vices et vertus: discours moral, invention littéraire et pensée esthétique (XVI ${ }^{e}-\mathrm{XVIII}{ }^{e}$ siècle)
}

\section{Monica Pavesio}

\section{(2) OpenEdition}

\section{Journals}

\section{Edizione digitale}

URL: http://journals.openedition.org/studifrancesi/15305

DOI: 10.4000/studifrancesi. 15305

ISSN: 2421-5856

\section{Editore}

Rosenberg \& Sellier

\section{Edizione cartacea}

Data di pubblicazione: 1 décembre 2018

Paginazione: 492-493

ISSN: 0039-2944

\section{Notizia bibliografica digitale}

Monica Pavesio, «Entre vices et vertus: discours moral, invention littéraire et pensée esthétique $\left(x v^{e}-x v I I{ }^{e}\right.$ siècle)», Studi Francesi [Online], 186 (LXII | III) | 2018, online dal 01 janvier 2019, consultato il 06 janvier 2021. URL: http://journals.openedition.org/studifrancesi/15305 ; DOI: https://doi.org/10.4000/ studifrancesi. 15305

Questo documento è stato generato automaticamente il 6 janvier 2021.

\section{(c) $)(1) \Theta$}

Studi Francesi è distribuita con Licenza Creative Commons Attribuzione - Non commerciale - Non opere derivate 4.0 Internazionale. 


\title{
Entre vices et vertus: discours moral, invention littéraire et pensée esthétique (XVI ${ }^{e}-X V I I I^{e}$ siècle)
}

\author{
Monica Pavesio
}

\section{NOTIZIA}

Entre vices et vertus: discours moral, invention littéraire et pensée esthétique (XVI ${ }^{e}-X V I I I^{e}$ siècle), sous la direction de A. AUDY-TROTTIER, K. GLADU, V. GODIN-FILION, N. GILIBERT, E. JOLY, Paris, Hermann 2016, 206 pp.

1 Il volume riunisce gli atti dell'undicesimo convegno, dedicato ai giovani ricercatori, del Cercle interuniversitaire d'étude sur la République des Lettres (CIERL).

2 Il discorso sulla morale, nell'epoca presa in esame (xvI, XVII e xvIII secolo), deve essere studiato grazie a discipline differenti, come la filosofia, l'antropologia, la letteratura, l'arte. Teologi, poeti, artisti, filosofi, uomini e donne della République des Lettres, si sono interrogati, durante l'Ancien Régime, sul binomio vizio e virtù, partendo dal campo religioso, passando a quello filosofico, per poi arrivare ad interrogarsi sull'uomo.

La prima parte del volume, intitolata "De l'horreur édifiante à la faillite de la vertu», riunisce alcuni saggi dedicati ad autori ed opere del XVII secolo. Il primo, scritto da T. CATEL, studia la nozione di mostruosità morale nelle Histoires tragiques (Exemplarité et écriture du monstrueux dans les histoires tragiques (1559-1644): le vice, entre édification morale et horreur prodigieuse, pp. 21-33); il secondo di J.A PERRAS analizza il dibattito intorno alla nozione di génie durante il XVII secolo ("Giroüettes à tous vents": le génie de la morale au xvile

siècleMaximes A. LAIDLILa vertu peut-elle ne pas être un "vice déguisé"? La question du "hors texte" et du non-dit dans les "Maximes" de La Rochefoucauld,J. PERRIER-CHARTRAND,pièceManlius 
CapitolinusLa faillite de la vertu aristocratique dans "Manlius Capitolinus" d'Antoine de La

Fosse,

4 La seconda sezione del libro, intitolata «La morale mise en scène: entre la naïveté de la fable et la licence picturale», è dedicata ai dibattiti sulla morale, con particolare attenzione all'ambito teatrale. Nel primo saggio (Querelle du théâtre et Querelle des femmes: convergences et lieux communs, pp. 83-93), v. DUPUIS ripercorre e compara la Querelle du théâtre, che inizia verso il 1550 e prosegue fino alla fine del XVI secolo, con la Querelle des femmes, più o meno dello stesso periodo, studiandone gli effetti nel XVII secolo. Il secondo lavoro di M.A. CROFT è dedicato a Edme Boursault ed alle sue comédies moralisantes (Le Pigeon qui voulait devenir Corneille ou la fable d'Edme Boursault 1638-1701, pp. 95-106).

5 Nella tre parti successive, «Le vice nécessaire à l'utilité publique; émergence d'une morale paradoxale», «Évolutions et révolutions de la parole chrétienne au XVIII ${ }^{\mathrm{e}}$ siècle» e «Les Lumières libertines et la morale: traditions et réecritures», l'attenzione si sposta sul XVIII secolo, quando nuove teorie economiche e sociali alimentano e diversificano il dibattito sulla morale. 